\title{
Study Day Range
}

National Cancer Institute

\section{Source}

National Cancer Institute. Study Day Range. NCI Thesaurus. Code C95349.

The relative timing for a planned or performed activity expressed as the number of days offset from the study-defined reference activity (e.g., date of registration, start of treatment) for this particular experimental unit. EXAMPLE(S): Day 1, Days 10-20 OTHER NAME(S): Study Day NOTE(S): The study-defined reference activity can be different from study to study. The study day for a date after this reference activity is a positive integer calculated as the difference in the two dates +1 . The study day for dates before the reference activity is a negative integer calculated as the difference between the two dates. Note that this means there is no "Day 0." 